\title{
BIAXIAL FLEXURAL STRENGTH AND HARDNESS OF RESIN-MATRIX CERAMIC CAD/CAM MATERIALS
}

\author{
SARAH M. ALNAFAIY*, "NAWAF LABBAN*, AHMED MAAWADH**, HUDA A. ALSHEHRI*, \\ ABDULLAH S. ALJAMHAN**, WEJDAN ALGHAMDI* \\ *Department of Prosthetic Dental Sciences, College of Dentistry, King Saud University, \\ Riyadh, Saudi Arabia \\ **Department of Restorative Dental Sciences, College of Dentistry, King Saud University, \\ Riyadh, Saudi Arabia \\ \#E-mail: nalabban@ksu.edu.sa
}

Submitted June 29, 2021; accepted July 27, 2021

Keywords: Ageing, Ceramic, Flexural Strength, Hybrid materials, Hardness

\begin{abstract}
This study evaluated the biaxial flexural strength (BFS) and hardness of four resin-matrix ceramic CAD/CAM materials namely, Vita Enamic (EN), Lava Ultimate (LU), Cerasmart (CS), Crystal Ultra (CU) and one glass-matrix ceramic material, Vitablocs Mark II (VM2). Disc-shaped specimens (12 mm in diameter and $1.2 \mathrm{~mm}$ in thickness) were prepared from the CAD/ CAM materials and were accordingly allocated into two groups. One group was used for baseline measurements and the other group was subjected to ageing by thermal-cycling (TC) for 10,000 cycles. The BFS and hardness was evaluated by a universal testing machine and a Vickers hardness tester, respectively. A two-way ANOVA, one-way ANOVA with Tukey's post hoc test, and Student's $t$-test $(=0.05)$ were used to analyse the data $(\alpha=0.05)$. The highest and lowest BFS was seen in CS and VM2 and the difference in the BFS among the materials was statistically significant $(p<0.05)$. The comparison between the baseline and TC groups showed significant difference in the BFS for EN ( $p<0.001), L U(p<0.001)$, and CS $(p<0.012)$ but no difference was seen for VM2 $(p=0.238)$ and $C U(p<0.159)$. The Vickers hardness number $(V H N)$ ranking of the materials for the baseline and TC specimens, was VM2 $>E N>L U>C S>C U$ and VM2 $>E N>L U>C U>C S$, respectively. Following the TC, all the materials showed a significantly lower VHN $(p<0.05)$ except for VM2 $(p=0.727)$. The CS material had the highest BFS among the baseline and TC groups; however, it had the lowest hardness among the materials in the baseline group and had comparable values to CU after the TC. Ageing by thermal-cycling significantly lowered the BFS of the CAD/CAM materials except for VM2 and CU, and lowered the hardness of the resin-matrix ceramic materials.
\end{abstract}

\section{INTRODUCTION}

In recent years, a wide array of ceramic dental materials have become available for routine clinical practice [1]. Ceramic materials are either classified into resin-matrix ceramics, glass-matrix ceramics or polycrystalline ceramics [2]. Resin-matrix ceramics are made up of an organic matrix that is densely packed with ceramic particles, and were developed to combine the benefits of both ceramic and composite resin materials. They combine the strength and aesthetic properties of ceramics and the elasticity and low abrasiveness of composite resins [3-7]. Specifically, the manufacturers' motive for developing resin-matrix ceramic materials was to create a material that more closely simulates the modulus of elasticity of dentin than conventional ceramics, to develop a material which is easier to mill and modify than certain groups of glass-matrix ceramics or polycrystalline ceramics, and to enable the repair or adjustment with composite resins [2]. Resin-matrix ceramics are recommended in areas to minimise the stress peaks during function, such as in implant prostheses $[8,9]$.

The fracture of the ceramic restorations is one of the most commonly reported mechanical failures.
Different reasons could lead to the fracture, such as the inadequate strength, improper design of the restoration and technical problems during machining [10]. The flexural strength is one of the predictors of a material's mechanical properties and is commonly used to classify and rank dental materials. The flexural strength is the extent to which the material can withstand stress or load, and predicts the nature of the material's microstructure [11]. Commonly, the flexural strength can be tested by uniaxial or biaxial strength tests. However, the biaxial flexural strength (BFS) test is the commonly employed method as it can simulate the multiaxial loading during mastication in the oral cavity. It has also shown that the BFS eliminates premature failure from edge defects parallel to the direction of load, which gives reliable defect detectability [12-14].

Hardness is the resistance to permanent indentation or penetration, and is considered as a second predictor of the mechanical properties of dental materials [15]. The hardness of ceramic materials can affect the wear resistance and ability to finish and polish the material, and its machinability [2, 5, 7]. The hardness can be tested by different methods such as Knoop, Vickers and Martens hardness tests. However, Vickers hardness tests 
has been the commonly employed method by researchers for hardness testing of dental materials [16-20]. Resin-ceramic materials have been demonstrated to have a lower hardness than glass-matrix and polycrystalline ceramics [17-21]. Furthermore, the hardness of resinceramic materials is directly proportional to the weight of the ceramic component in the resin-ceramic material [19].

Thermal cycling is one of the most widely applied aging processes in laboratory research, simulating the thermal changes that occur inside the oral cavity, therefore the clinical performance of the material [22, 23, 24]. Resin-matrix ceramic materials have demonstrated a significant decrease in hardness values while glass ceramics showed no significant changes after thermal-cycling [25]. The decreased effects in the hardness of resin-matrix ceramic materials are attributed to the water absorption of the resin structure during thermal-cycling [26-28].

A variety of resin-matrix ceramic materials have become available in recent years such as Vita Enamic (EN), Lava Ultimate (LU), Cerasmart (CS), and Crystal Ultra (CU). Crystal Ultra is a recently developed hybrid ceramic material, and is available in the form of blocks and discs to fabricate full-arch implant supported prostheses, crowns, bridges and abutments. The manufacturer claims that $\mathrm{CU}$ has the lowest Young's modulus (10 $000 \mathrm{MPa}$ ) among the currently available resin-matrix ceramic materials. Its flexibility makes the material recommended to be used for implant dentistry, acting as a shock absorber to withstand the masticatory forces. This material is assumed to be lighter than ceramics and stronger than acrylics, and presents with a Vickers hardness number which closely matches the dentin structure $[8,9,29]$. Nevertheless, there are a lack of studies to demonstrate the physico-mechanical properties of this material that could also validate the manufacturer's claim.
Therefore, the objective of this laboratory study was to evaluate the BFS and hardness of a new material (crystal ultra) in comparison with contemporary ceramic and resin matrix ceramic CAD/CAM materials. The hypothesis was that there is no significant difference in the BFS and hardness between the tested CAD/CAM materials. Furthermore, ageing by thermal-cycling will not have a significant effect on the BFS and hardness of the tested $\mathrm{CAD} / \mathrm{CAM}$ materials.

\section{EXPERIMENTAL}

\section{Specimen preparation}

The mechanical properties (BFS and hardness) of four different $\mathrm{CAD} / \mathrm{CAM}$ resin-matrix ceramic materials with similar clinical indications and one glass-matrix ceramic material was tested. The sample size and dimension were in accordance with previous studies for the BFS [30] and hardness [25] tests. Table 1 lists the materials used in the present study.

Thirty disc-shaped specimens measuring $12 \mathrm{~mm}$ in diameter and $1.2 \mathrm{~mm}$ in thickness were prepared from each study material for the BFS and VHN test. The specimens for VM2, EN, LU and CS were obtained from $12 \times 14 \times 18 \mathrm{~mm} \mathrm{CAD} / \mathrm{CAM}$ blocks, whereas the specimens for CU were obtained from $15 \times 15 \times 38.8 \mathrm{~mm}$ CAD/CAM blocks. The blocks were initially milled using a milling unit (Ceramill Motion 2, Amann Girrbach AC, Koblach, Austria) to obtain cylindrical blocks with a diameter of $12 \mathrm{~mm}$. Then, the blocks were sliced to the desired thickness of $1.20 \mathrm{~mm}$ using an automated saw (IsoMet 1000 Precision, Buehler, Bluff, IL, USA). The dimension of each specimen was verified using a digital micrometre (Digimatic Micrometer; Mitutoyo, Japan), and any variations in the dimensions were

Table 1. Materials used in the study.

\begin{tabular}{|c|c|c|}
\hline Material & Manufacturer & Composition \\
\hline $\begin{array}{l}\text { Vitablocs } \\
\text { Mark II (VM2) }\end{array}$ & $\begin{array}{l}\text { Vita Zahnfabrik, H. Rauter GmbH \& Co, } \\
\text { Bad Sackingen, Germany }\end{array}$ & $\begin{array}{l}\text { Feldspathic ceramic }\left(56-64 \% \mathrm{SiO}_{2}, 20-23 \% \mathrm{Al}_{2} \mathrm{O}_{3} \text {, }\right. \\
\left.6-9 \% \mathrm{Na}_{2} \mathrm{O}, 6-8 \% \mathrm{~K}_{2} \mathrm{O}\right)\end{array}$ \\
\hline $\begin{array}{l}\text { Lava Ultimate } \\
(\mathrm{LU})\end{array}$ & 3M ESPE, St. Paul, MN, USA & $\begin{array}{l}80 \% \text { ceramic }\left(69 \% \mathrm{SiO}_{2}, 31 \% \mathrm{ZrO}_{2}\right) 20 \text { wt. \% cross linked po- } \\
\text { lymer matrix }\left(\mathrm{BisGMA}^{1)}, \mathrm{UDMA}^{2)}, \mathrm{BisEMA}^{3)} \text { and TEGDMA }{ }^{4)}\right)\end{array}$ \\
\hline $\begin{array}{l}\text { Vita Enamic } \\
\text { (VE) }\end{array}$ & $\begin{array}{l}\text { Vita Zahnfabrik, H. Rauter GmbH \& Co, } \\
\text { Bad Sackingen, Germany }\end{array}$ & $\begin{array}{l}86 \% \text { feldspathic based-ceramic }\left(58-63 \% \mathrm{SiO}_{2}, 20-23 \% \mathrm{Al}_{2} \mathrm{O}_{3} \text {, }\right. \\
\left.9-11 \% \mathrm{Na}_{2} \mathrm{O}, 4-6 \% \mathrm{~K}_{2} \mathrm{O}, 0-1 \% \mathrm{ZrO}_{2}\right), 14 \text { wt. } \% \text { cross-linked } \\
\text { polymers }\left(\mathrm{BisGMA}{ }^{1)} \text {, and UDMA }{ }^{2)} \text { infiltrated into }\right. \\
\text { feldspathic-based ceramic network }\end{array}$ \\
\hline $\begin{array}{l}\text { Cerasmart } \\
(\mathrm{CS})\end{array}$ & GC America, Alsip, IL, USA & $\begin{array}{l}71 \text { wt. \% silica and barium glass nanoparticles; } 29 \text { wt. \% } \\
\text { cross-linked polymers }\left(\text { BisMEPP }^{5)}, \text { UDMA }^{2)} \text {, and DMA }\right.\end{array}$ \\
\hline $\begin{array}{l}\text { Crystal Ultra } \\
(\mathrm{CU})\end{array}$ & Digital Dental, Scottsdale, AZ, USA & $\begin{array}{l}70 \text { wt. \% ceramic-like inorganic silicate glass filler particles } \\
30 \text { wt. \% cross-linked polymers }\left(\text { BisGMA }^{1)}, \mathrm{UDMA}^{2)} \text {, and }\right. \\
\text { BUDMA }^{7)} \text { ) }\end{array}$ \\
\hline
\end{tabular}

Note: 1) bisphenol-A-glycidyldimethacrylate; 2) Urethane Dimethacrylate; 3) Ethoxylated bisphenol A dimethacrylate; 4) triethyleneglycoldimethacrylate; 5) Bisphenol A bis (2-hydroxyethyl ether) dimethacrylate; 6) Dimethacrylate; 7) 1,4-butanediol dimethacrylate 
rectified by replacing the specimen with a new one.

The specimens were embedded in a vinyl polysiloxane putty to prepare the specimen for the polishing process. The surfaces of the specimens were polished in a polishing machine (LaboPol-25; Struers) using different grit sizes $(400,600,800,1000$, and 1200) of silicon carbide paper (Water Proof SiC Paper; Struers) at $300 \mathrm{rpm}$ under water. Following polishing, the specimens were cleaned using distilled water in an ultrasonic bath (Quantrex 90 WT, L\&R Manufacturing, Inc., Kearny, NJ, USA) for $10 \mathrm{~min}$ and air dried for $40 \mathrm{~s}$ [30].

The specimens from each study material were randomly allocated to two groups $(n=15)$. The first group served as the baseline and the other group was subjected to artificial ageing by thermal-cycling (TC). The specimens in the control group were immersed in distilled water at room temperature for $24 \mathrm{~h}$ before the BFS test. The specimens in the TC group were aged by for 10,000 thermal-cycles (CS-4.2, THE-1100, SDMechatronik, Germany) in distilled water. The thermocycler was operated at temperatures between $5{ }^{\circ} \mathrm{C}$ and $55^{\circ} \mathrm{C}$ with a dwell time of $15 \mathrm{~s}$ and a transfer time of $5 \mathrm{~s}$.

\section{Biaxial flexural strength}

$$
\text { (BFS) testing }
$$

Thirty specimens were used for the BFS test $(n=$ $=30$ ) and the testing procedure was in accordance with the technical report of the International Organization for Standardization for ceramic materials ISO/TR6872:2015 [31]. The specimen was symmetrically placed on three $3.2 \mathrm{~mm}$ diameter stainless steel balls positioned $120^{\circ}$ apart in a circle at a diameter of $10 \mathrm{~mm}$ (Fig. 1a) on the sample holder of a universal testing machine (Instron Machine 5969; Instron Corporation, Norwood, MA, USA). The specimens were then loaded by a piston (1.2 $\mathrm{mm}$ in diameter) at the centre with a cross-head speed of $0.5 \mathrm{~mm} \cdot \mathrm{min}^{-1}$ until fracture (Figure 1b). The fracture load was recorded and the BFS was calculated using the following Equation 1 [30].

$$
\begin{gathered}
S=-0.2387 \mathrm{P}(\mathrm{X}-\mathrm{Y}) / \mathrm{d}^{2} \\
x=(1+v) \ln \left(r_{2} / r_{3}\right)^{2}+([1-v] / 2)\left(r_{2} / r_{3}\right)^{2} \\
\left.\mathrm{Y}=(1+v) 1+\ln \left[r_{1} / r_{3}\right]\right)^{2}+(1-v)\left(r_{1} / r_{3}\right)^{2}
\end{gathered}
$$

where $S$ is the BFS in $\mathrm{MPa}, P$ is the fracture load in N; $d$ is the specimen thickness at the fracture site in $\mathrm{mm}$; $v$ is Poisson's ratio (0.25), $r_{1}$ is the diameter of support circle $(5 \mathrm{~mm}) ; r_{2}$ is the diameter of the loaded area $(0.6 \mathrm{~mm})$; and $r_{3}$ is the diameter of the specimen $(6 \mathrm{~mm})$.

\section{Scanning electron microscopy (SEM) analysis}

Following the BFS test, the representative specimen from both the baseline and thermal-cycled groups were subjected to a SEM analysis (JEOL JSM-IT800, Tokyo, Japan). Prior to the SEM analysis, a specimen

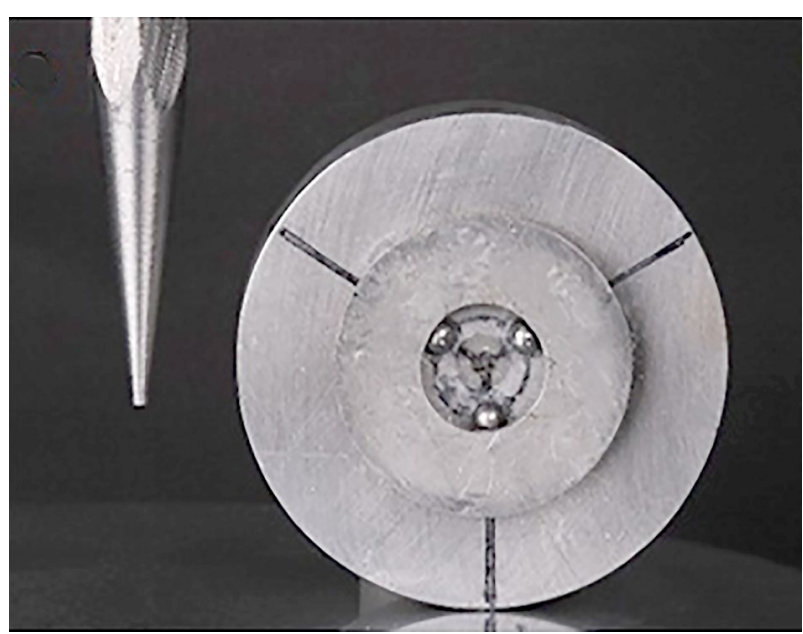

a)

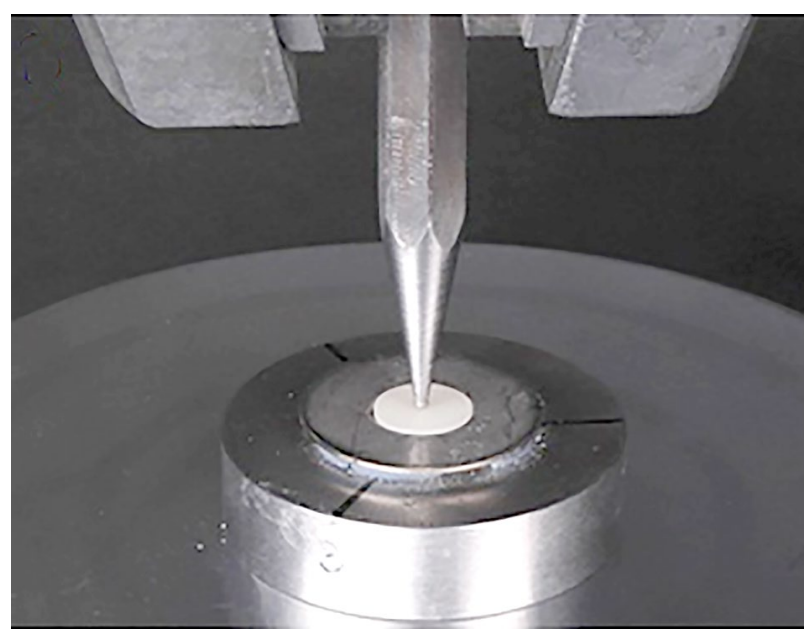

b)

Figure 1. Close view of the piston and the stainless-steel balls (a) and biaxial flexural strength test setup (b).

from each study material was mounted on an aluminium stub and gold sputter coated (Smart Coater, JEOL USA, Inc., MA, USA) for $120 \mathrm{~s}$. The SEM analysis was completed at a voltage of $20 \mathrm{kV}$, in a vacuum and with a $2500 \times$ magnification.

\section{Hardness $(\mathrm{H})$ test}

Ten specimens $(n=10)$ were randomly allocated into two groups (baseline and thermal-cycled). The immersion and ageing process for the baseline and TC groups followed the same procedure as in the BFS test, respectively. The hardness of the specimens was evaluated using a hardness tester equipped with a Vickers indenter (NOVA 130/240 IMP, INNOVATEST, Netherlands, Europe). Five indentations were performed for each specimen $2 \mathrm{~mm}$ apart under a load of $200 \mathrm{gf}$ and a dwell time of $10 \mathrm{~s}$. The Vickers hardness number (VHN) was calculated using the following Equation 2 [25]: 


$$
H=1.854 \cdot \frac{F}{d^{2}}
$$

where $H$ is the Vickers hardness number, $F$ is the load $(\mathrm{N})$ and $d$ is the indentation diagonal length ( $\mathrm{mm})$.

\section{Statistical analysis}

All the data analyses were performed using statistical software (IBM SPSS Inc., v.22, Chicago, IL, USA). The normal distribution of the data was tested by means of the Kolmogorov-Smirnov test and all the data were distributed normally. A two-way analysis of variance (ANOVA) was used to evaluate the effect of the material and ageing on the BFS and hardness. A oneway ANOVA with Tukey's post-hoc analysis was used to test the significant difference between the baseline and thermal-cycled groups. Student's t-test was used to determine the significant difference between two material groups before and after the thermal-cycling within each material. A $p$-value $<0.05$ was used to report the statistical significance of the results.

\section{RESULTS}

\section{Biaxial flexural strength}

The two-way ANOVA to test the effect of the material and ageing factors on the BFS is presented in Table 1 . The independent factors, namely the material type, aging, and the interaction between them had a significant effect on the BFS $(\mathrm{p}<0.05)$.

The mean BFS of the study materials at the baseline and after the TC are presented in Figure 2. Among the baseline specimens, the one-way ANOVA showed that the resin-matrix ceramic $\mathrm{CAD} / \mathrm{CAM}$ material, namely $\mathrm{CS}$, had the highest BFS values followed by LU and EN. The difference in the BFS between these materials was statistically significant $(p<0.05)$. The lowest values were observed with the CU and VM2 materials and the difference between them was statistically non-significant $(p>0.05)$. The BFS of the TC group demonstrated the highest values for CS followed by LU and the difference in the BFS between these materials was statistically significant $(p<0.001)$. On the contrary, the BFS values were lower with $\mathrm{CU}<\mathrm{VM} 2>\mathrm{EN}$; however, the difference in the BFS between them was non-significant $(p>0.05)$.

The comparison between the baseline and the TC groups showed a significant difference in the BFS for EN $(p<0.001)$, LU $(p<0.001)$, and CS $(p<0.012)$. On the contrary, no significant difference was found between the baseline and the TC group for the materials VM2 ( $p=$ $=0.238)$ and $\mathrm{CU}(p<0.159)$ (Student's t-test) (Figure 2).

\section{SEM evaluation}

The SEM micrographs of the representative test specimens comparing the baseline and TC specimens are presented in Figure 4. The resin-matrix ceramic

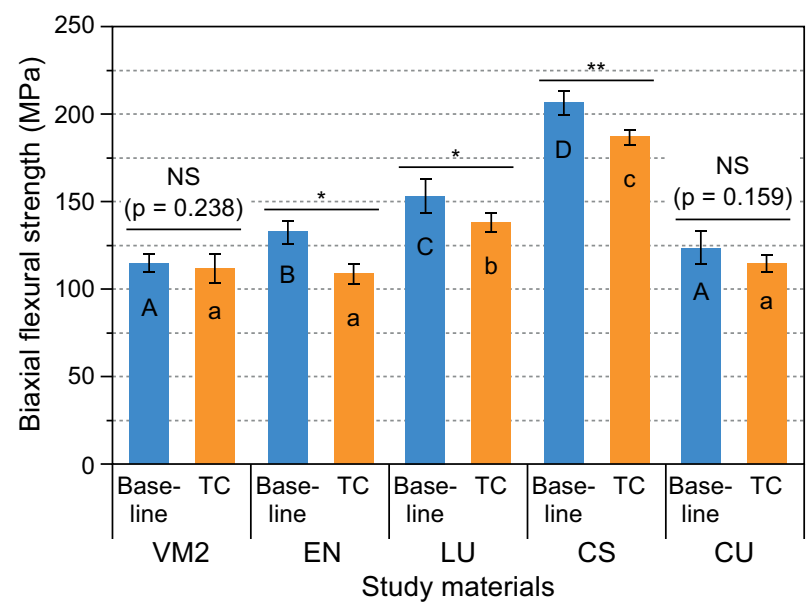

Figure 2. Mean and SD of the biaxial flexural strength test. *Statistically significant difference between the baseline and thermal-cycled specimens of the same material group $(p<$ 0.001) (Student t-test); ${ }^{* *}$ Statistically significant difference between the baseline and thermal-cycled specimens of the same material group $(p<0.012$ ) (Student t-test). Different upper case letters indicate a statistically significant difference between the baseline specimens $(p<0.05)$ (One-way ANOVA); Different lower case letters indicate a statistically significant difference between the thermal-cycled specimens $(p<0.05)$ (One-way ANOVA).

Table 1. Two-way ANOVA for the interaction between the material type and the ageing on the biaxial flexural strength.

\begin{tabular}{lccrrc}
\hline Source & Type III sum of squares & df & Mean square & F & Significant \\
\hline Corrected model & $152926.172 \mathrm{a}$ & 9 & 16991.797 & 99.935 & $<0.001^{*}$ \\
Intercept & 2899861.501 & 1 & 2899861.501 & 17055.071 & $<0.001^{*}$ \\
Material & 143268.430 & 4 & 35817.108 & 210.653 & $<0.001^{*}$ \\
Ageing & 7563.868 & 1 & 7563.868 & 44.486 & $<0.001^{*}$ \\
Material* ageing & 2093.873 & 4 & 523.468 & 3.079 & 0.018 \\
Error & 23804.099 & 140 & 170.029 & - & - \\
Total & 3076591.773 & 150 & - & - & - \\
Corrected total & 176730.271 & 149 & - & - & - \\
\hline
\end{tabular}

Note: Type III Sum of Squares infers a significant effect and the interaction of the material and the ageing of the material on the biaxial flexural strength. $D F=$ Degrees of Freedom (N-1); F value = variation between the sample means/variation within the samples; *Statistically Significant $(p<0.05)$ 
materials namely, EN, LU, CS, and CU, demonstrated pores and microcracks between the inorganic and organic components in the thermal-cycled groups. CU specimen showed the least surface changes after TC compared to the other resin-matrix ceramic materials. On the contrary, the VM2 specimens had no noticeable differences between the baseline and the TC groups.

\section{Hardness}

The two-way ANOVA to test the effect of the material and ageing factors on the VHN is presented in Table 3. The independent factors, namely the material type and the ageing, and the interaction between these factors significantly influenced the VHN $(p<0.05)$.

The mean VHN of the CAD/CAM materials at the baseline and following TC are presented in Figure 3. Among the baseline and TC specimens, the VHN ranking of the materials was $\mathrm{VM} 2>\mathrm{EN}>\mathrm{LU}>\mathrm{CS}>$ $>\mathrm{CU}$ and $\mathrm{VM} 2>\mathrm{EN}>\mathrm{LU}>\mathrm{CU}>\mathrm{CS}$, respectively. The feldspathic ceramic material, VM2, demonstrated the highest VHN at both the baseline and TC to the resin matrix ceramic materials. There was a significant difference in the VHN between the five materials at the baseline and TC $(p<0.05)$ except for CS and CU following the TC $(p>0.05)$.

Following the $\mathrm{TC}$, all the resin matrix ceramic CAD/CAM materials showed a significantly lower VHN compared to the baseline VHN $(p<0.05)$. However, the feldspathic ceramic VM2 showed no significant difference in the VHN between the baseline and TC groups $(p=0.727)$.

\section{DISCUSSION}

Manufacturers report the strength measurements for their products under ideal conditions. While this information is valuable, how the properties of these materials change after exposure to various stresses is more practical for clinicians. Limited independent research has been published on the strengths and limitations of these CAD/CAM materials, specifically how their properties change with ageing. The objective of the present study was to evaluate the biaxial flexural strength (BFS) and hardness of resin ceramic $\mathrm{CAD} / \mathrm{CAM}$ materials. Furthermore, the study also evaluated the effect of ageing by thermal-cycling (TC) on the BFS and hardness of the tested materials. The results of the study advocate the rejection of the null hypothesis as the studied CAD/ CAM materials demonstrated a significant difference in the BFS and hardness at both the baseline and following the TC.

BFS test is one of the primary tests to predict the fracture strength and the long-term clinical performance of any new material as it simulates the multiaxial forces that occur during mastication in the oral cavity. The BFS test has also showed to be more reliable than a uniaxial flexural strength test because the maximum stresses occur in the central areas rather than the edges, thus edge failures are eliminated [12-14]. A piston-on-three-ball BFS test was used in this study because it is the only adopted test by International Organization for Standards (ISO/TR-6872:2015) for dental ceramic materials

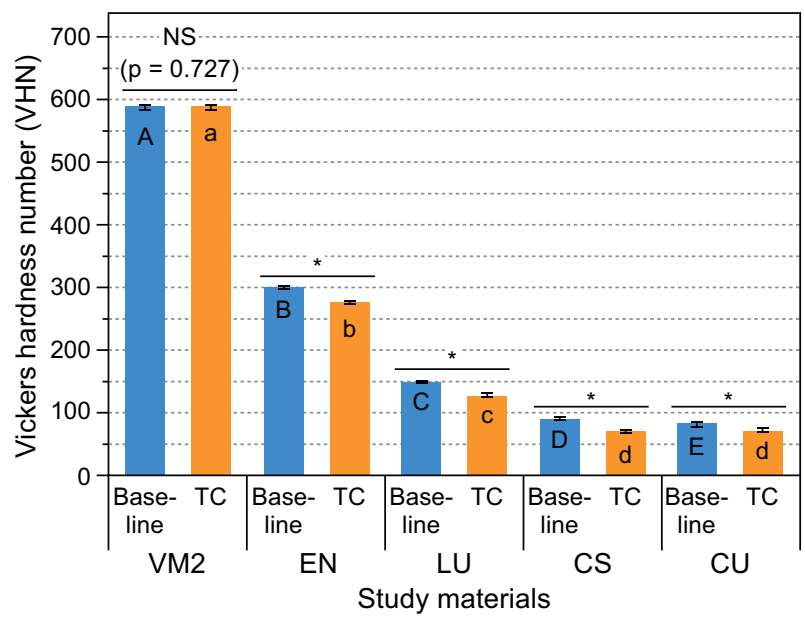

Figure 3. Mean and SD of the hardness test.

*Statistically significant difference between the baseline and thermal-cycled specimens of the same material group $(p<0.001)$ (Student t-test). Different upper case letters indicate a statistically significant difference between the baseline specimens $(p<0.05)$ (One-way ANOVA); Different lower case letters indicate a statistically significant difference. $(p<0.05)$

Table 3. Two-way ANOVA for the interaction between the material type and the ageing on the Vickers Hardness Number (VHN).

\begin{tabular}{lccrrc}
\hline Source & Type III sum of squares & df & Mean square & F & Significant \\
\hline Corrected Model & $1848130.608 \mathrm{a}$ & 9 & 205347.845 & 324490.428 & $<0.001^{*}$ \\
Intercept & 2739768.294 & 1 & 2739768.294 & 4329378.691 & $<0.001^{*}$ \\
Material & 1844342.030 & 4 & 461085.508 & 728606.786 & $<0.001^{*}$ \\
Ageing & 2860.629 & 1 & 2860.629 & 4520.363 & $<0.001^{*}$ \\
Material* ageing & 927.948 & 4 & 231.987 & 366.586 & $<0.001^{*}$ \\
Error & 25.313 & 40 & $? ? ? .633$ & - & - \\
Total & 4587924.215 & 50 & - & - & - \\
Corrected Total & 1848155.921 & 49 & - & - & - \\
\hline
\end{tabular}

Note: Type III Sum of Squares infers a significant effect and the interaction of the material and ageing of the material on the VHN. DF $=$ Degrees of Freedom (N-1); F value = variation between the sample means / variation within the samples. *Statistically Significant ( $p<0.05)$. 


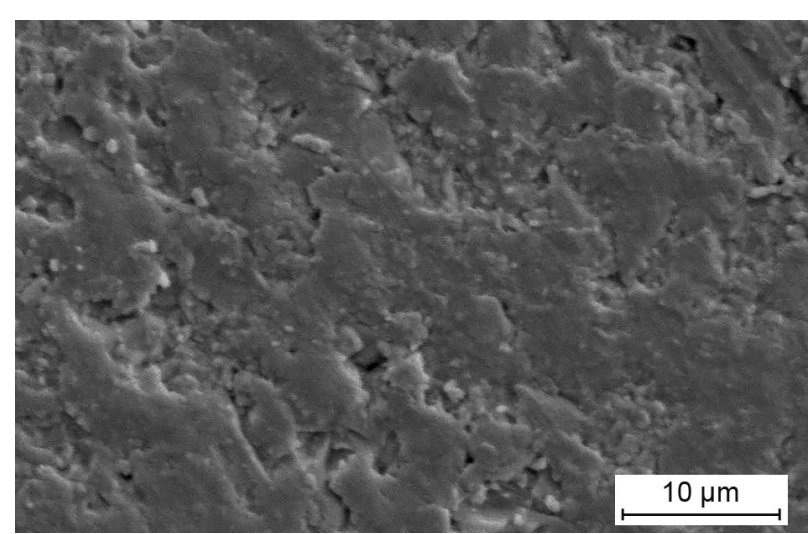

a) VM2 - baseline

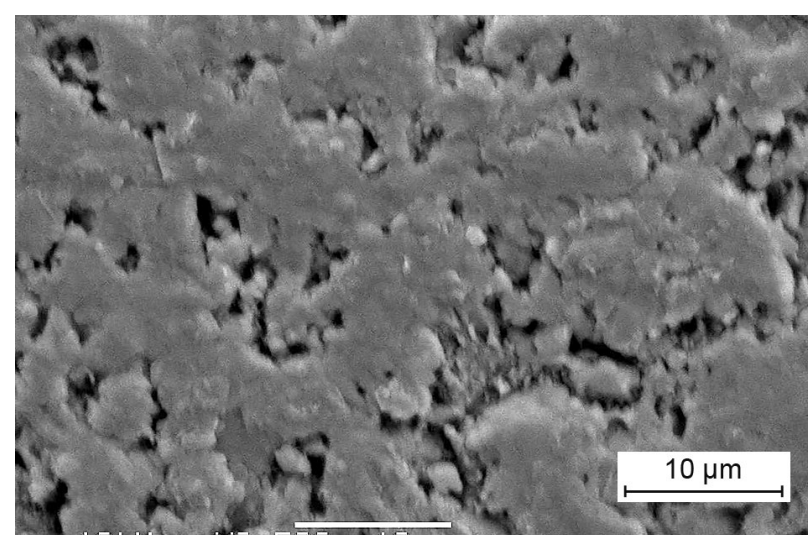

c) EN - baseline

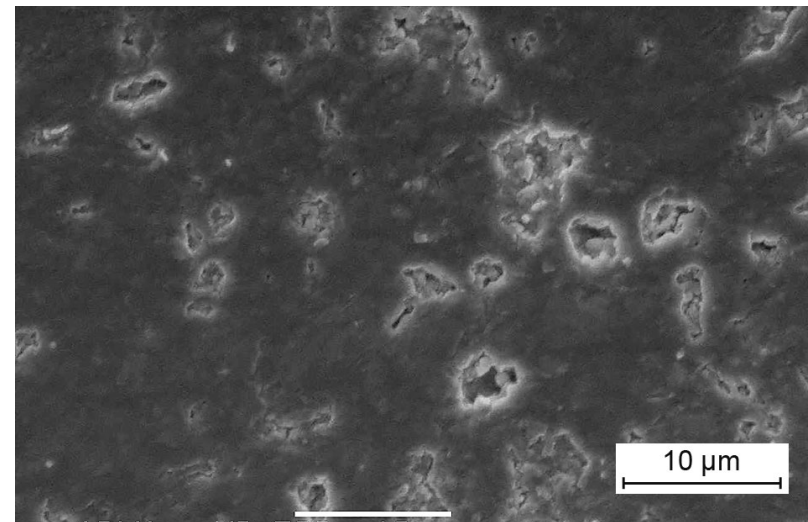

e) LU - baseline

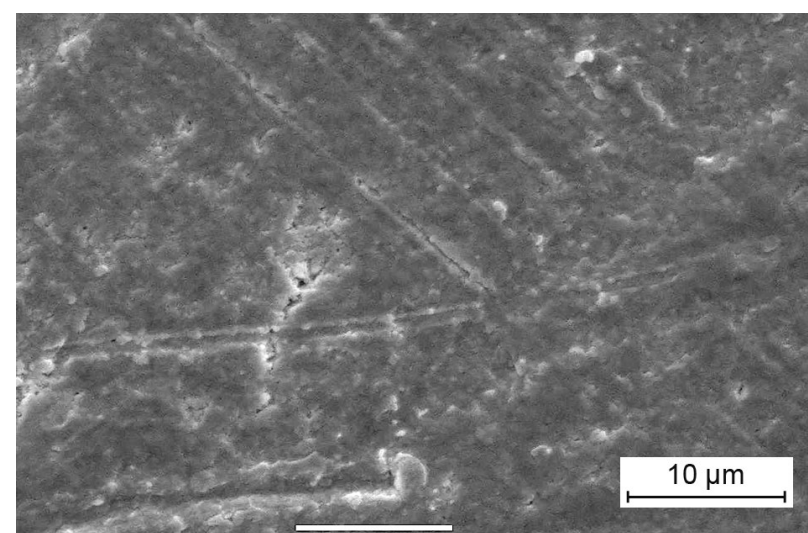

g) CS - baseline

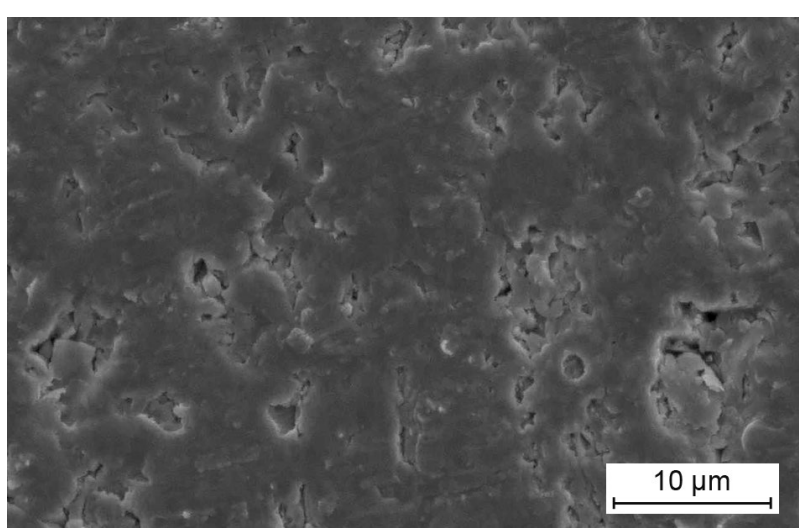

b) VM2 - thermal-cycled

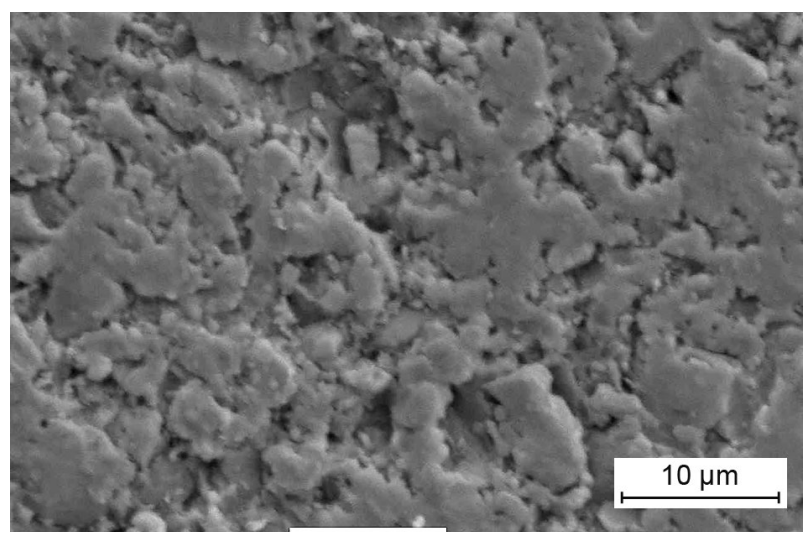

d) EN - thermal-cycled

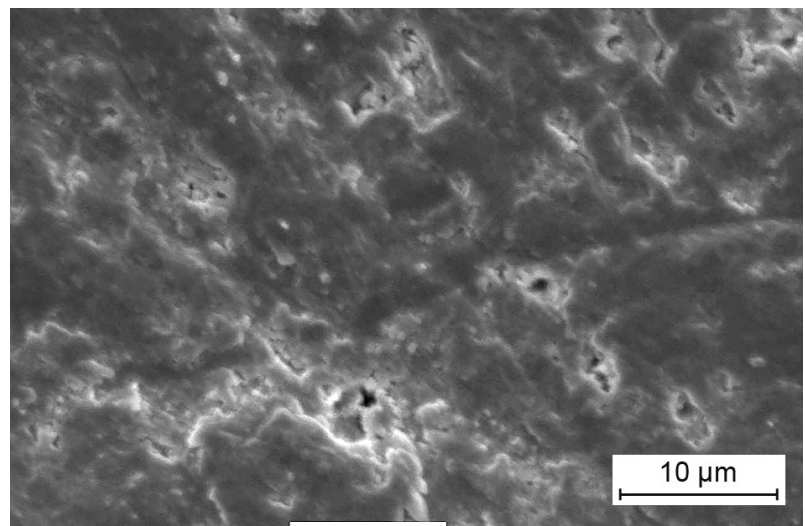

f) LU - thermal-cycled

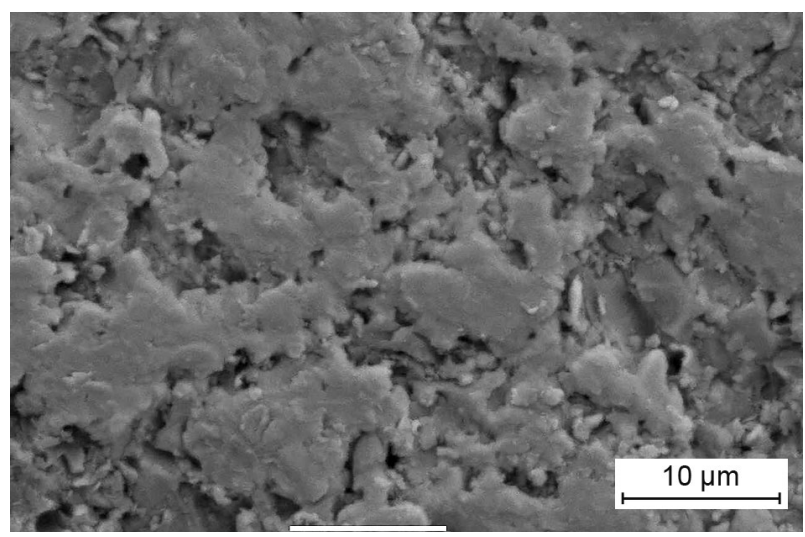

h) $\mathrm{CS}$ - thermal-cycled

Figure 4. SEM micrographs of the fractured surfaces following the BFS test. (Continue on next page) 


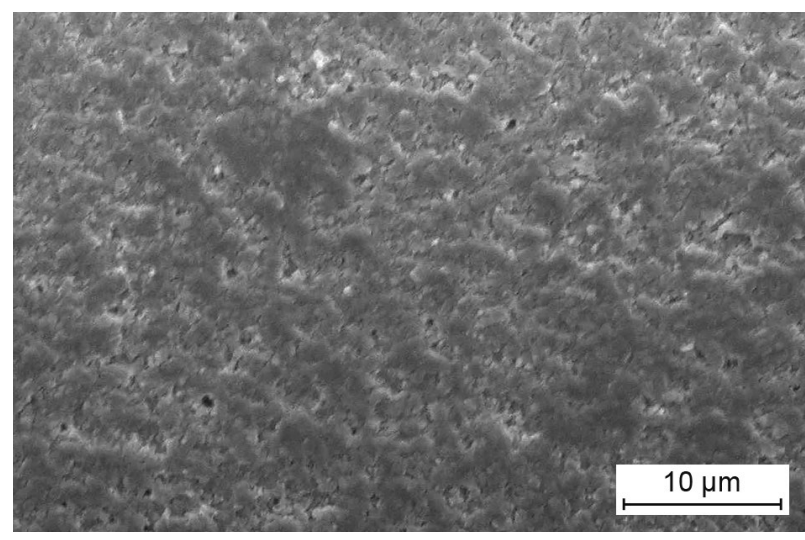

i) CU - baseline

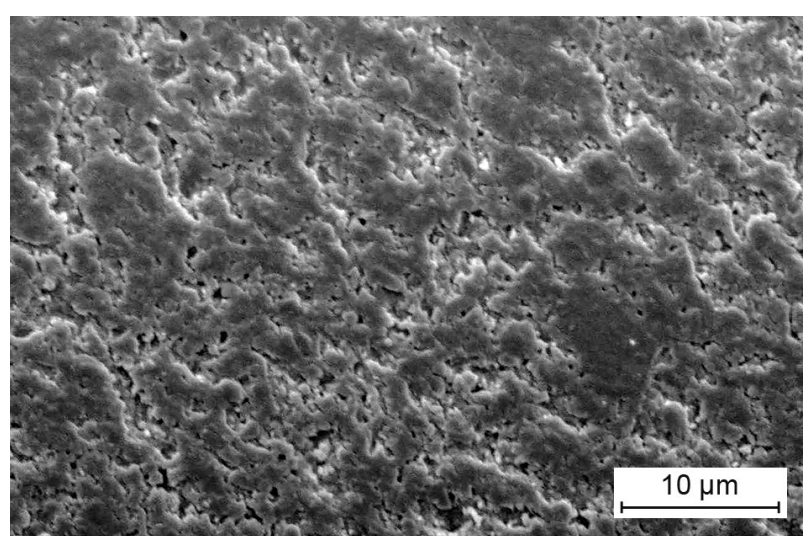

j) CU - thermal-cycled

Figure 4. SEM micrographs of the fractured surfaces following the BFS test.

$[32,33]$. The BFS of the materials was tested at a baseline and following 10,000 TC to simulate the thermal changes inside the oral cavity.

One commonly used procedure to simulate the physiological ageing encountered by biomaterials in clinical practice is thermocycling [34]. Thermal changes inside the oral cavity can cause the material to undergo repeated cycles of expansion and contraction, leading to mechanical stresses and crack formation. The number of TCs applied in this study was equivalent to one year of clinical function based on the assumption of Gale and Darvell where dental restorations are subjected to abrupt thermal changes 20 times per day. The temperature settings between $5{ }^{\circ} \mathrm{C}$ and $55^{\circ} \mathrm{C}$ temperatures and a $15 \mathrm{~s}$ dwell time are the most commonly used thermal settings in studies, as these temperatures are advocated by the ISO $11405[22,35]$. For all the tested materials, the results showed that the BFS decreased after the TC except for VM2 and CU, and this could be related to the thermal fatigue within the polymer component of the resin-matrix ceramic materials [26-28]. CU has high polymer/ceramic ratio, however it has one type of ceramic particles homogeneously incorporated and bonded by covalent bond with the resin matrix, compared to the other hybrid materials that have different types of ceramic fillers, and this could justify its non-significant decreased BFS. [26$28,43,46]$. The one-way ANOVA test results showed that CS had significantly higher BFS values among the tested materials with/without the TC and this is related to its homogeneously dispersed nanosized ceramic fillers compared to the other materials. Nanoceramic materials have also shown to increase the resistance to mechanical degradation due to the matrix-filler coupling mechanism $[36,37]$. On the contrary, VM2 had the lowest values due its weak glass matrix and irregularly-shaped crystalline particles that make the material more brittle than the other materials. Furthermore, the toughening mechanism of the resin-matrix ceramic materials surpassed the flexural strength of VM2 [30, 38]. LU had lower BFS values than CS as its ceramic particles are larger. In contrast, it had significantly higher BFS values than EN and CU and this could be related to its high zirconia content that reinforces the structure of the material [30].

The present study findings are in agreement with previous studies where the BFS of CS, LU, EN and VM2 was evaluated without TC $[30,39,40]$. Concerning the $\mathrm{TC}$, one study evaluated the BFS of LU and EN after TC (5000 cycles at temperature between $5{ }^{\circ} \mathrm{C}$ and $55^{\circ} \mathrm{C}$ ), and the results were consistent with this study as the strength of LU was higher than EN [40]. The BFS of the new CU material was comparable to VM2, but lower than other materials at the baseline. CU and CS have a comparable composition; however, the ceramic particles of $\mathrm{CU}$ are larger than the nanosized ceramic particles of CS and this could explain its lower BFS. [36, 37] The $70 \%$ ceramic component of $\mathrm{CU}$ is based on silica and is only compared to LU and EN which are reinforced with zirconia, alumina and other particles. Alumina and zirconia particles have showed to enhance the mechanical properties of ceramic materials compared to silica particles $[41,42]$. On the contrary, the BFS of $\mathrm{CU}$ was less affected by the TC than EN giving higher BFS values despite that they were not significant and this could be explained by the strong covalent bond of the silica particles with the resin matrix [43].

The hardness is the second important property to be tested with any new material, as it affects the polishing capability of the material and the wear resistance $[5,7,44]$. The test results found that hardness was directly proportional to the weight of the ceramic component in the materials significantly with and without TC following previous studies concerning CS, LU, EN, and VM2 [9, $16,17,21,45]$. On the contrary, only two studies found no significant difference between the hardness of EN and LU and this may be attributed to the differences in the hardness test $[19,25]$. The hardness of CU was lower than CS in the control groups due to the higher polymer/ ceramic ratio, however they were comparable to the CS values after the TC. These comparable values could be attributed to the high bond strength between the $\mathrm{CU}$ silica fillers in the resin-matrix compared to the CS ones which are composed of silica particles and barium glass 
particles, which, therefore, are less affected by the water [43]. The water sorption of the barium glass filled resin has shown to be high as the barium glass fillers could be damaged by the water, leaving water at the interface between the fillers and the resin matrix, thus, affecting the mechanical properties [46]. On the contrary, a lower hardness has shown to present with few advantages to dental materials, such as improving the milling process that results in minimal chipping at the margin and less bur damage $[5,7,17]$. It was also shown that ceramic materials with a lower hardness than enamel (VHN-274.8) presented with less antagonist wear [18, 19, 47-49].

Among the tested materials, a significant difference in the hardness was found between the baseline and the TC groups except for VM2. This decreased effect in the hardness of resin-matrix ceramic materials is related to the water absorption in the resin structure during the TC. Water absorption leads to enlargement of the material network and hydrolysis of the silane coupling agent between the fillers and resin matrix [26-28]. These finding are in agreement with previous studies where the hardness was evaluated with and without TC for CS, LU, EN, and VM2 [9, 16, 17, 19, 21, 45]. In the study of Sonmez et al. [25], the SEM micrographs showed microcracks and structure deteriorations in the EN and LU materials after the TC, which is in agreement with the outcome of the present study.

This study is an in-vitro study that does not completely simulate the intra-oral environment. The actual results could vary depending on routine intra-oral activities. Further studies are required to evaluate properties of these resin-matrix materials under more simulated intra oral ageing, such as those including beverages, tooth brushing, and mastication.

\section{CONCLUSION}

CS had the highest BFS values, significantly followed by LU, then EN, whereas the new CU and VM2 had the lowest values in the control groups. The same findings were found after the TC except that EN showed comparable values to CU and VM2. The hardness of the tested materials showed significant differences between the $\mathrm{CAD} / \mathrm{CAM}$ materials that range from high to low in the order of $\mathrm{VM} 2>\mathrm{EN}>\mathrm{LU}>\mathrm{CS}>\mathrm{CU}$; however, $\mathrm{CS}$ and $\mathrm{CU}$ had no significant difference after the TC.

The thermal-cycling had a significant effect on the $\mathrm{BFS}$ of the CAD/CAM materials except for VM2 and $\mathrm{CU}$, and on the hardness of the resin-matrix ceramic materials.

\section{Acknowledgments}

The authors would like to thank the College of Dentistry Research Centre, King Saud University, Saudi Arabia for the approval and support (Registration No. PR 0107).

\section{REFERENCES}

1. Alfouzan A., Al-Otaibi H., Labban N., Al Taweel S., AlTuwaijri S., AlGazlan A., Tashkandi E. (2020): Effects of thickness and background color on the translucency of cad/ cam ceramic materials. Ceramics-Silikáty, 64, 418-422. doi: 10.13168/cs.2020.0029

2. Gracis S., Thompson V.P., Ferencz J.L., Silva N.R., Bonfante E.A. (2015): A new classification system for all-ceramic and ceramic-like restorative materials. International Journal of Prosthodontics, 28, 227-235. doi:10.11607/ijp.4244

3. Awada A., Nathanson D. (2015): Mechanical properties of resin-ceramic $\mathrm{CAD} / \mathrm{CAM}$ restorative materials. The Journal of Prosthetic Dentistry, 114, 587-593. doi: 10.1016/ j.prosdent.2015.04.016

4. Coldea A., Swain M.V., Thiel N. (2013): In-vitro strength degradation of dental ceramics and novel PICN material by sharp indentation. Journal of the Mechanical Behavior of Biomedical Materials, 26, 34-42. doi: 10.1016/j.jmbbm. 2013.05.004

5. Lebon N., Tapie L., Vennat E., Mawussi B. (2015): Influence of $\mathrm{CAD} / \mathrm{CAM}$ tool and material on tool wear and roughness of dental prostheses after milling. The Journal of Prosthetic Dentistry, 114, 236-247. doi: 10.1016/j.prosdent. 2014.12.021

6. Ruse N.D., Sadoun M.J: (2014). Resin-composite blocks for dental CAD/CAM applications. Journal of Dental Research, 93, 1232-1234. doi: 10.1177/0022034 514553976

7. Tsitrou E.A., Northeast S.E., van Noort R. (2007): Brittleness index of machinable dental materials and its relation to the marginal chipping factor. Journal of Dentistry, 35, 897-902. doi: 10.1016/j.jdent.2007.07.002

8. de Kok P., Kleverlaan C.J., de Jager N., Kuijs R., Feilzer A.J. (2015): Mechanical performance of implant-supported posterior crowns. The Journal of Prosthetic Dentistry, 114, 59-66. doi: 10.1016/j.prosdent.2014.10.015

9. Lauvahutanon S., Takahashi H., Shiozawa M., Iwasaki N., Asakawa Y., Oki M., Finger W.J., Arksornnukit M. (2014): Mechanical properties of composite resin blocks for CAD/CAM. Dental Materials Journal, 33, 705-710. doi: 10.4012/dmj.2014-208

10. Lemos C.A.A., Verri F.R., Gomes J.M.L., de Souza Batista V.E., Cruz R.S., Oliveira H., Pellizzer E.P. (2019): Ceramic versus metal-ceramic implant-supported prostheses: A systematic review and meta-analysis. The Journal of Prosthetic Dentistry, 121, 879-886. doi: 10.1016/j.prosdent.2018.09. 016

11. Danzer R. (2014): On the relationship between ceramic strength and the requirements for mechanical design. Journal of the European Ceramic Society 34, 3435-3460. doi: 10.1016/j.jeurceramsoc.2014.04.026

12. Börger A., Supancic P., Danzer R. (2002): The ball on three balls test for strength testing of brittle discs: stress distribution in the disc. Journal of the European Ceramic Society, 22, 1425-1436. doi: 10.1016/S0955-2219(01) 00458-7

13. Chung S.M., Yap A.U., Chandra S.P., Lim C.T. (2004): Flexural strength of dental composite restoratives: comparison of biaxial and three-point bending test. Journal of Biomedical Materials Research B Applied Biomaterials 71, 278-283. doi: 10. 1002/jbm.b.30103

14. Palin W.M., Fleming G.J., Burke F.J., Marquis P.M., Randall R.C. (2003): The reliability in flexural strength testing of a novel dental composite. Journal of Dentistry, 
31, 549-557. doi: 10.1016/s0300-5712(03)00110-6

15. Wang L., D’Alpino P.H., Lopes L.G., Pereira J.C. (2003): Mechanical properties of dental restorative materials: relative contribution of laboratory tests. Journal of Applied Oral Sciences, 11, 162-167. doi: 10.1590/S1678-77572003 000300002

16. Goujat A., Abouelleil H., Colon P., Jeannin C., Pradelle N., Seux D., Grosgogeat B. (2018): Mechanical properties and internal fit of 4 CAD-CAM block materials. The Journal of Prosthetic Dentistry, 119, 384-389. doi: 10.1016/j.prosdent. 2017.03.001

17. Lawson N.C., Bansal R., Burgess J.O. (2016): Wear, strength, modulus and hardness of $\mathrm{CAD} / \mathrm{CAM}$ restorative materials. Dental Materials, 32, e275-e283. doi: 10. 1016/j. dental.2016.08.222

18. Ludovichetti F.S., Trindade F.Z., Werner A., Kleverlaan C.J., Fonseca R.G. (2018): Wear resistance and abrasiveness of CAD-CAM monolithic materials. The Journal of Prosthetic Dentistry, 120, 318.e1-318.e8. doi: 10.1016/j.prosdent. 2018.05.011

19. Mormann W.H., Stawarczyk B., Ender A., Sener B., Attin T., Mehl A. (2013): Wear characteristics of current aesthetic dental restorative $\mathrm{CAD} / \mathrm{CAM}$ materials: two-body wear, gloss retention, roughness and Martens hardness. Journal of Mechanical Behavior of Biomedical Materials, 20, 113-125. doi: 10.1016/j.jmbbm.2013.01.003

20. Niem T., Youssef N., Wöstmann B. (2019): Energy dissipation capacities of CAD-CAM restorative materials: A comparative evaluation of resilience and toughness. The Journal of Prosthetic Dentistry, 121, 101-109. doi: 10.1016/ j.prosdent.2018.05.003

21. Albero A., Pascual A., Camps I., Grau-Benitez M. (2015): Comparative characterization of a novel cad-cam polymer-infiltrated-ceramic-network. Journal of Clinical and Experimental Dentistry, 7, e495-500. doi: 10.4317/jced. 52521

22. Morresi A.L., D’Amario M., Capogreco M., Gatto R., Marzo G., D'Arcangelo C., Monaco A. (2014): Thermal cycling for restorative materials: does a standardized protocol exist in laboratory testing? A literature review. Journal of the Mechanical Behavior of Biomedical Materials, 29, 295-308. doi: 10.1016/j.jmbbm.2013.09.013

23. Mazzitelli C., Monticelli F., Toledano M., Ferrari M., Osorio R. (2012): Effect of thermal cycling on the bond strength of self-adhesive cements to fiber posts. Clinical Oral Investigations, 16, 909-915. doi: 10.1007/s00784011-0576-1

24. Mesquita R.V., Geis-Gerstorfer J. (2008): Influence of temperature on the visco-elastic properties of direct and indirect dental composite resins. Dental Materials, 24, 623-632. doi: 10.1016/j.dental.2007.06.025

25. Sonmez N., Gultekin P., Turp V., Akgungor G., Sen D., Mijiritsky E. (2018): Evaluation of five CAD/CAM materials by microstructural characterization and mechanical tests: a comparative in vitro study. BMC Oral Health, 18, e5. doi: 10.1186/s12903-017-0458-2

26. Druck C.C., Pozzobon J.L., Callegari G.L., Dorneles L.S., Valandro L.F. (2015): Adhesion to Y-TZP ceramic: study of silica nanofilm coating on the surface of Y-TZP. Journal of Biomedical Materials Research B Applied Biomaterials, 103, 143-150. doi: 10.1002/jbm.b.33184

27. He L.H., Purton D., Swain M. (2011): A novel polymer infiltrated ceramic for dental simulation. Journal of Mate- rial Sciences: Materials in Medicine, 22, 1639-1643. doi: 10.1007/s10856-011-4350-3

28. Zhi L., Bortolotto T., Krejci I. (2016): Comparative in vitro wear resistance of $\mathrm{CAD} / \mathrm{CAM}$ composite resin and ceramic materials. The Journal of Prosthetic Dentistry, 115, 199-202. doi: 10.1016/j.prosdent.2015.07.011

29. Al Amri M.D., Labban N., Alhijji S., Alamri H., Iskandar M., Platt J.A. (2021): In Vitro Evaluation of Translucency and Color Stability of CAD/CAM Polymer-Infiltrated Ceramic Materials after Accelerated Aging. Journal of Prosthodontics, 30, 318-328. doi: 10.1111/jopr.13239

30. Sen N., Us Y.O. (2018): Mechanical and optical properties of monolithic CAD-CAM restorative materials. The Journal of Prosthetic Dentistry, 119, 593-599. doi: 10.1016 /j. prosdent. 2017.06.012

31. ISO/TR-6872:2015(E). (2015): Technical Report: Dentistry-ceramic materials. In. Geneva, International Organization for Standardization.

32. Jin J., Takahashi H., Iwasaki N. (2004): Effect of test method on flexural strength of recent dental ceramics. Dental Materials Journal, 23, 490-496. doi: 10.4012/dmj.23.490

33. Shetty D.K., Rosenfield A.R., Duckworth W.H., Held P.R. (1983): A Biaxial-Flexure Test for Evaluating Ceramic Strengths. Journal of the American Ceramic Society, 66, 36-42. doi: 10.1111/j.1151-2916.1983.tb09964.x

34. Blackburn C., Rask H., Awada A. (2018): Mechanical properties of resin-ceramic CAD-CAM materials after accelerated aging. The Journal of Prosthetic Dentistry, 119, 954-958. doi: 10.1016/j.prosdent.2017.08.016

35. Gale M.S., Darvell B.W. (1999): Thermal cycling procedures for laboratory testing of dental restorations. Journal of Dentistry, 27, 89-99. doi: 10.1016/S0300-5712(98) 00037-2

36. Egilmez F., Ergun G., Cekic-Nagas I., Vallittu P.K., Lassila L.V.J. (2018): Does artificial aging affect mechanical properties of CAD/CAM composite materials. Journal of Prosthodontic Research, 62, 65-74. doi: 10.1016/j.jpor. 2017.06.001

37. Manhart J., Kunzelmann K.H., Chen H.Y., Hickel R. (2000): Mechanical properties of new composite restorative materials. Journal of Biomedical Materials Research, 53, 353-361. doi: 10.1002/1097-4636

38. Lohbauer U., Petschelt A., Greil P. (2002): Lifetime prediction of CAD/CAM dental ceramics. Journal of Biomedical Materials Research, 63, 780-785. doi:10.1002/ jbm.10468

39. Choi B.J., Yoon S., Im Y.W., Lee J.H., Jung H.J., Lee H.H. (2019): Uniaxial/biaxial flexure strengths and elastic properties of resin-composite block materials for CAD/CAM. Dental Materials, 35, 389-401. doi: 10.1016/j.dental.2018. 11.032

40. Yin R., Kim Y.K., Jang Y.S., Lee J.J., Lee M.H., Bae T.S. (2019): Comparative evaluation of the mechanical properties of CAD/CAM dental blocks. Odontology, 107, 360-367. doi: 10.1007/s10266-018-0407-9

41. Elsaka S.E., Elnaghy A.M. (2016): Mechanical properties of zirconia reinforced lithium silicate glass-ceramic. Dental Materials, 32, 908-914. doi:10.1016/j.dental. 2016.03.013

42. Shenoy A.,Shenoy N. (2010): Dental ceramics: An update. Journal of Conservative Dentistry, 13, 195-203. doi: 10. 4103/0972-0707.73379

43. Rodríguez H.A., Casanova H. (2018): Effects of Silica Nanoparticles and Silica-Zirconia Nanoclusters on Tribological Properties of Dental Resin Composites. Journal 
of Nanotechnology, 2018, 7589051. doi: 10.1155/2018/ 7589051

44. Ferro K.J., Morgano S.M. (2017): The Glossary of Prosthodontic Terms: Ninth Edition. The Journal of Prosthetic Dentistry, 117, e1-e105. doi: 10.1016/j.prosdent.2016.12. 001

45. Kim S.-H., Choi Y.-S., Kang K.-H., Att W. (2021): Effects of thermal and mechanical cycling on the mechanical strength and surface properties of dental CAD-CAM restorative materials. The Journal of Prosthetic Dentistry. (In Press). doi:10.1016/ j.prosdent.2020.11.014

46. Tarumi H., Torii M.,Tsuchitani Y. (1995): Relationship between particle size of barium glass filler and water sorption of light-cured composite resin. Dental Materials
Journal, 14, 37-44. doi:10.4012/dmj.14.37

47. Chun K., Choi H., Lee J. (2014): Comparison of mechanical property and role between enamel and dentin in the human teeth. Journal of Dental Biomechanics, 5, 1758736014520809. doi:10.1177/1758736014520809

48. Lawson N.C., Janyavula S., Syklawer S., McLaren E.A., Burgess J.O. (2014): Wear of enamel opposing zirconia and lithium disilicate after adjustment, polishing and glazing. Journal of Dentistry, 42, 1586-1591. doi:10.1016/j. jdent.2014.09.008

49. Turgut S.,Bagis B. (2011): Colour stability of laminate veneers: an in vitro study. Journal of Dentistry, 39, 12. doi:10.1016/j.jdent.2011.11.006 